\title{
URGENSI SELF DIRECTED LEARNING MAHASISWA AKTIVIS DI ERA REVOLUSI INDUSTRI 4.0 \\ (Studi Kasus Di Program Studi Pendidikan Agama Islam Universitas Ahmad Dahlan Yogyakarta)
}

\author{
Sutipyo Ru'iya \\ E-mail: sutipyo@pai.uad.ac.id \\ Dosen Fakultas Agama Islam \\ Universitas Ahmad Dahlan Yogyakarta
}

\begin{abstract}
Abstrak
Mahasiswa merupakan aset bangsa yang tidak ternilai harganya dan merupakan calon pemimpin di masa yang akan datang. Mahasiswa yang tergolong aktivis, baik di kampus mapun di luar kampus akan membutuhkan waktu ekstra ketat untuk memanage agar dapat membagi dengan bijaksana untuk mengejar tuntutan prestasi, terutama di era Revolusi Industri 4.0 ini. Secara psikologis mahasiswa harus mempunyai strategi yang jitu, agar dapat mencapai cita-citanya dengan baik. Penelitian ini melibatkan 50 orang mahasiswa Program Studi Pendidikan Agama Universitas Ahmad Dahlan Yogyakarta, yang diambil secara acak dari 150 mahasiswa aktivis yang ada. Hasil penelitian menunjukkan bahwa mahasiswa aktivis di Prodi PAI UAD mempunyai self directed learning yang tinggi, sehingga mereka mempunyai prestasi yang tinggi pula.
\end{abstract}

\section{Kata Kunci: Prestasi Akademik, Self Directed Learning, Mahasiswa Aktivis}

\section{Abstract}

Students are a national asset that is priceless and is a future leader in the future. Students who are classified as activists, whether on campus or off campus, will need extra tight time to manage so that they can share wisely to pursue the demands of achievement, especially in the era of the Industrial Revolution 4.0. Psychologically, students must have a precise strategy, so they can achieve their goals well. This study involved 50 students of the Ahmad Dahlan University Religious Education Study Program in Yogyakarta, which were taken randomly from 150 activist students. The results showed that activist students at PAI UAD Study Program had high self-directed learning, so they had high achievements.

\section{Keywords: Academic Achievement, Self Directed Learning, Activist Students}


Sutipyo Ru'iya : Urgensi Self Directed Learning Mahasiswa Aktivis Di Era Revolusi Industri 4.0

\section{A. PENDAHULUAN}

Keberadaan mahasiswa sangat strategis untuk perbaikan kualitas sumber daya manusia dimasa yang akan datang, sebagaimana pepatah Arab yang berarti "Pemuda masa kini adalah pemimpin dimasa yang akan datang". Mahasiswa yang sedang menuntut ilmu secara garis besar dapat dibagi menjadi tiga, yaitu mahasiswa yang hanya kuliah, mahasiswa yang kuliah sambil bekerja, dan mahsiswa yang kuliah sambil aktif di beberapa organisasi. Bagi mahasiswa yang kuliah saja, dari segi waktu cukup tersdia banayak, karena pada kenyataannya tidak setiap hari mereka kuliah. Waktu yang tersedia selain kuliah di kelas atau praktikum, dapat digunakan untuk belajar dan menambah ilmu secara mandiri.

Lain halnya dengan mahasiswa yang mempunyai aktivitas lain seperti sambil bekerja atau yang aktif di berbagai organisasi dan kegitan lain. Waktu mereka cukup tersita, untuk kegiatan aktivitas yang mereka geluti. Mahasiswa yang bekerja, harus dapat membagi waktu antara kuiah dan bekerja. Mahasiswa yang aktif diberbagai aktivitas juga harus dapat membagi waktu dan strategi belajar agar prestasi akademik mereka tetap baik.

Mahasiswa Program Studi Pendidikan Agama Islam Universitas Ahmad Dahlan Yogyakarta juga banyak yang aktif di berbagai organisasi, baik di organisasi kemahasiswaan kampus maupun di luar kampus. Organisasi yang di kampus misalnya Himpunan Mahasiswa Program Studi, Badan Eksekutif Mahasiswa, Ikatan Mahasiswa Muhammadiyah, Sahabat Dakwah, Media Center, Resimen Mahasiswa, Tapak Suci, Pramuka, dan lain-lain. Mahasiswa ini selain aktif sebagai mahasiswa yang dituntut untuk kuliah minimal $75 \%$ kehadiran 
pada setiap mata kuliah yang ambil, mereka juga menyebar dalam setiap kegiatan di aktifitas luar kuliah.

Mahasiswa yang memiliki peran dan status ganda, sebagai mahasiswa sekaligus sebagai anggota organisasi bukan berarti tanpa halangan yang berarti. Selain mengerjakan kewajiban utama sebagai mahasiswa, mereka juga harus memperhatikan aktivitas organisasi. Hasil penelitian Masitoh (dalam Caesari, Listiara, dan Ariati, 2013), menunjukkan bahwa mahasiswa yang aktif dalam organisasi cenderung mengalami konflik peran atau inter-role conflict. Mahasiswa yang tidak dapat mengatasi konflik dalam menjalani peran ganda yang dilalui, ada kecenderungan untuk kurang bisa menjalankan dan mengatur aktivitas perkuliahan dan organisasi, sehingga prestasi akademik mereka cenderung rendah.

Pada penelitian lain, disebutkan bahwa mahasiswa yang aktif di berbagai kegiatan kemahasiswaan mendapatkan manfaat yang besar, diantaranya berupa pengalaman yang kuat dalam keorganisasian, yang dinilai penting untuk mengembangkan kepribadian mahasiswa yang sangat penting terutama dalam ketika mereka manapaki dunia kerja (Caesari, Listiara, dan Ariati, 2013). Lebih lanjut Caesari, Listiara, dan Ariati (2013) mengutip hasil penelitian Cahyaningtyas yang menghasilkan kesimpulan bahwa tingkat kecerdasan emosional (EQ) mahasiswa yang aktif dalam organisasi lebih tinggi dibandingkan mahasiswa yang tidak aktif, sebagaimana yang dikatakan oleh Daniel Goleman bahwa IQ hanya menyumbang hanya sekitar $20 \%$ dari kesuksesan prestasi seseorang, sementara 80\% lainnya dipengaruhi oleh kecerdasan yang lain. 
Sutipyo Ru'iya : Urgensi Self Directed Learning Mahasiswa Aktivis Di Era Revolusi Industri 4.0

Pengamatan sekilas yang dilakukan peneliti pada prestasi akademik mahasiswa yang aktif berorganisasi di Program Studi Pendidikan Agama Islam Univesitas Ahmad Dahlan cenderung baik. Inilah yang memotivasi peneliti untuk mengetahui lebih jauh, self directed learning dari mahasiswa PAI UAD. Menurut beberapa penelitian diketahui bahwa bagi orang yang sibuk dan memperoleh prestasi akademik baik biasanya karena mereka juga mempunyai self directed learning yang baik.

Merriam \& Caffarella (dalam Gibbons, 2002; Nazleli, 2012) mendefinisikan self directed learning sebagai proses di mana orang-orang berinisiatif untuk perencanaan, melaksanakan, dan mengevaluasi pembelajaran yang akan dan atau telah mereka lakukan. Tujuan self directed learning juga cukup beragam, yaitu meliputi tercapainya potensi individu yang sepenuhnya, mendorong diri untuk melakukan perubahan, belajar beradaptasi dalam proses emansipatoris (Baumgartner, 2003).

Frederick, Blumenfeld, \& Paris, (2004) dalam Latipah (2010) mengatakan bahwa preastasi belajar juga erat hubungannya dengan self regulated learning terutama bagi siswa SMP dan SMU. Sementara itu, Read (2000) dalam Rachmawati (2010) mengatakan bahwa self-directed learning meliputi apa yang menjadi kebutuhan dari pembelajaran (individual learning needs), karakteristik belajar (individual learning characteristics), dan aktivitas belajar mandiri (self-directed learning activities) untuk mencapai kepuasan dalam (learning satisfaction).

Self directed learning lebih menekankan kepada pembahasan keunikan gaya belajar seorang mahasiswa dan melakukan otonomi belajarnya sehingga mereka dengan bebas dan terencana menentukan aktivitas belajar, memonitoring, dan mengevaluasi hasil belajarnya secara mandiri. Oleh karena itu, 
Sutipyo Ru'iya : Urgensi Self Directed Learning Mahasiswa Aktivis Di Era Revolusi Industri 4.0

Song \& Hill (2007) mengatakan bahwa self-directed learning meliputi tiga hal antara lain perencanaan (planning), meninjau pelaksanaan (monitoring), dan evaluasi (evaluating).

Dari latar belakang di atas, fokus penelitian ini "Bagaimana Self Directed Learning Mahasiswa Aktivis Program Studi Pendidikan Agama Islam Universitas Ahmad Dahlan dalam menghadapi era Revolus 4.0 agar prestasi akademik mereka tetap terjaga dengan baik?”

\section{B. METODE}

Subyek penelitian penelitian adalah mahasiswa aktivis pada Program Studi Pendidikan Agama Islam yang terdiri dari kelas Wates dan kelas Yogyakarta. Jumlah populasi mahasiswa aktivis 150 orang, namun pada penelitian ini subyek diambil secara acak sebanyak 50 orang.

Pengumpulan data menggunakan skala Self-Directed Learning (SDL) yang diadabtasi dari karya Gibbon (2002). Sedangkan prestasi akademik diperoleh melalui data dokumen Fakultas Agama Islam. Skala SDL yang digunakan dalam penelitian ini telah dilakukan validitas dan reliabilitas melalui uji statistik. Hasil uji statistik SDL di peroleh nilai Cronbach's Alpha sebesar 0,909 dan tergolongan sangat baik. Data yang terkumpul lalu dilakukan analisis dengan menggunakan analisis Uji Korelasi Spearman's Rho menggunakan analisis program SPSS 21.

\section{PEMBahasan}

1. Prestasi akademik

Prestasi merupakan bentuk perolehan dari suatu tujuan tertentu melalui suatu usaha yang panjang, dan 
Sutipyo Ru'iya : Urgensi Self Directed Learning Mahasiswa Aktivis Di Era Revolusi Industri 4.0

ditetakan melalui hasil tes atau ujian. Chaplin (2011) mengemukakan bahwa achievement atau peratasi merupakan hasil yang telah dicapai. Menurut Winkel (1987) prestasi akademik merupakan hasil penilaian kepada seseorang dibidang pengetahuan, keterampilan, dan sikap sebagai penampakan dari hasil belajar dan dinyatakan dalam bentuk nilai.

Prestasi akademik didefinisikan oleh Good (dalam Ambekdar, 2012) sebagai sikap pengetahuan atau keterampilan yang dikembangkan dalam mata pelajaran di sekolah, biasanya ditentukan oleh nilai tes atau dengan tanda yang diberikan oleh guru. Akibatnya, prestasi didefinisikan sebagai hasil evaluasi dari keberhasilan dari tujuan seseorang.

Latipah (2010) juga mengatakan bahwa prestasi akademik merupakan kinerja belajar seseorang yang pada umumnya ditunjukkan dalam bentuk nilai rata-rata yang diperoleh. Di perguruan tinggi biasanya nilai rata-rata selanjutnya dimunculkan dalam bentuk indeks prestasi (IP).

Dari beberapa definisi di atas dapat disimpulkan bahwa yang dimaksud dengan pratasi akademik mahasiswa adalah unjuk kinerja seorang mahasiswa yang diperoleh dari hasil belajarnya yaitu meliputi kemampuan pengetahuan, keterampilan dan sikap, yang diperlihatkan dalam bentuk nilai rata-rata dalam bentuk indeks prestasi (IP).

Belajar di perguruan tinggi sedikit berbeda dengan belajar di tingkat sekolah dasar, sekolah menengah, maupun di sekolah tingkat atas. Di sekolah dasar, menengah dan tingkat atas, prestasi belajar biasanya diukur dengan hasil ujian tengah semester (UTS) dan ujian akhir semester (UAS). 
Sutipyo Ru'iya : Urgensi Self Directed Learning Mahasiswa Aktivis Di Era Revolusi Industri 4.0

Faktor lain, khususnya seperti tugas-tugas mandiri sangat minim dijadikan perhitungan dalam penentuan nilai akhir sebuah mata pelajaran. Lain halnya dengan prestasi akademik di perguruan tinggi yang unsur penilaiannya lebih kompleks. Selain nilai hasil sangat berkaitan dengan UTS dan UAS, penilaian diperguruan tinggi biasanya ditentukan oleh banyak unsur, seperti tugas-tugas mandiri dan tugas-tugas presentasi.

Prestasi akademik di perguruan tinggi membutuhkan kemampuan kognitif yang tinggi dan kemampuan psikomotoris dan kemampuan verbal. Kemampuan kognitif yang harus diimplementasikan dalam bentuk penyusunan makalah dan tugas-tugas mandiri merupakan salah satu ciri khas penilaian yang ada diperguruan tinggi. Hasil yang diperoleh oleh peserta didik (mahasiswa) dari hasil belajarnya tersebut biasanya dalam bentuk indeks prestasi (Latipah, 2010). Pada penelitian ini, peneliti juga akan menggunakan Indeks Prestasi Mahasiswa Program Studi PAI sebagai tolak ukur tinggi rendahnya prestasi akademik mahasiswa.

2. Self Directed Learning (SDL)

Menurut Knowles (dalam, Tennant, 2006), yang dimaksud dengan self-directed learning adalah sebuah inisiatif yang diambil seorang individu, dengan atau tanpa bantuan orang lain, setelah dindividu tersebut mendiagnosa dan merumuskan tujuan belajarnya, mengidentifikasi sumber dan materi belajarnya, memilih dan menerapkan strategi belajar yang tepat dan mengevaluasi hasil belajarnya. Begitu pula menurut Merriam \& Caffarella (dalam Gibbons, 2002) yang dimaksud dengan self-directed learning adalah sebuah proses di mana seseorang mengambil inisiatif untuk 
Sutipyo Ru'iya : Urgensi Self Directed Learning Mahasiswa Aktivis Di Era Revolusi Industri 4.0

merencanakan, melaksanakan, dan mengevaluasi cara belajarnya yang telah dan akan mereka lakukan sendiri.

Menurut Gibbons (2002) yang dimaksud dengan selfdirected learning adalah peningkatan pengetahuan, keahlian, prestasi, dan mengembangkan diri yang dilakukan oleh seorang individu dengan cara banyak metode dalam berbagai macam situasi dan dalam waktu yang berbeda-beda pula. Oleh karena itu Bandura (dalam Tennant, 2006) menyimpulkan yang dimaksud dengan self-directed learning (SDL) adalah berkaitan dengan kontrol diri seseorang dalam belajarnya.

Dari beberapa pendapat di atas dapat disimpulkan bahwa yang dimaksud dengan self-directed learning (SDL) dalam penelitian ini adalah inisiatif kontrol diri yang dilakukan oleh seorang mahasiswa dalam merencanakan, melaksanakan, dan mengevaluasi proses belajarnya, sehingga dia dapat memperoleh prestasi yang baik.

Menurut Gibbons (2002), ada lima dimensi selfdirected learning antara lain:

a. Kontrol diri dalam belajar

Mengontrol diri dari segala akibat dari luar maupun dalam dirinya, sehingga seseorang mempunyai fokus yang kuat akan tercapainya apa yang diinginkan. Seseorang mulai menerima dan melaksanakan tanggungjawanya, memilih dan memutuskan segala kegiatan dan memilih metode dan cara penyelesaian masalahnya sesuai dengan konsisi dirinya sendiri. Segala perbuatan yang dilakukan diarahkan oleh dirinya (selfdirecting), untuk mencapai tujuan yang diinginkan, 
Sutipyo Ru'iya : Urgensi Self Directed Learning Mahasiswa Aktivis Di Era Revolusi Industri 4.0

sehingga segala proses yang dilakukan dapat berjalan efektif dan efisien.

b. Pengembangan keterampilan

Melakukan negoisasi diri sehingga menjadi sebagai kontrak dengan dirinya sendiri bahwa seseroang akan selalu meningkatkan keterampilannya secara independen. Dengan demikian seseorang akan selalu mengindetifikasi kepentingan dirinya, melengkapinya, dan berusaha untuk mewujudkannya secara maksimal.

c. Pengubahan diri pada kinerja yang lebih baik

Berani mengambil resiko atas segala apa yang dilakukannya, karena segala apa yang dilakukan telah melalui perhitungan yang matang. Oleh karena itu, seseorang dengan mantap dalam melakukan suatu pekerjaan dengan kinerja yang maksimal.

d. Manajemen diri

Melakukan pengelolaan diri yang sungguhsungguh, sehingga mereka selalu berupaya memfokuskan segala aktifitasnya untuk menuju pada keberhasilannya. Oleh karena itu, mereka selalu melakukan monitoring terhadap perencanaan dan pelaksanaan yang akan dan telah dilakukan.

e. Motivasi dan penilaian diri

Menumbuhkan keyakinan, keberanian dan tekad dalam dirinya untuk memberi energi pada setiap usaha yang akan dilakukannya. Dengan demikian, mereka akan terampil dalam mengelola waktu dan sumber daya yang mereka miliki untuk mencapai tujuan. Mereka dapat memobolisir segala daya dan kemampuannya untuk mencapai tujuannya. Mereka dengan cepat pula mencari 
Sutipyo Ru'iya : Urgensi Self Directed Learning Mahasiswa Aktivis Di Era Revolusi Industri 4.0

dan memberi solusi dari setiap hambatan yang dihadapi dalam rangka mempertahankan produktifitas diri secara efektif.

3. Hasil dan Analisis

a. Variabel Prestasi Akademik

Berdasarkan hasil data penelitian yang diperoleh maka dapat dideskripsikan masing-masing variabel prestasi akademik mahasiswa aktivis Program Studi Pendidkan Agaa Islam pada tabel berikut:

Tabel 1. Deskripsi Prestasi akademik

\begin{tabular}{|l|c|c|c|}
\hline \multicolumn{1}{|c|}{ Katagori } & IPK & Jumlah & Prosentase \\
\hline $\begin{array}{l}\text { Dengan Pujian } \\
\text { (Cumlaude) }\end{array}$ & $3,51-4,00$ & 43 & $86 \%$ \\
\hline $\begin{array}{l}\text { Sangat } \\
\text { Memuaskan }\end{array}$ & $3,01-3,50$ & 7 & $14 \%$ \\
\hline Memuaskan & $2,51-3,00$ & 0 & 0 \\
\hline
\end{tabular}

Berdasarkan tabel 1 di atas diketahui bahwa mayoritas Prestasi akademik mahasiswa aktivis di Program Studi Pendidikan Agama Islam berada pada predikat cumlaude atau berada pada presdikat Indek Prestasi dengan pujian mencapai $86 \%$. Sisanya $14 \%$ berada pada kategori sangat memuaskan. Indeks prestasi akademik mahasiswa aktivis di Program Studi Pendidikan agama Islam di atas 3.00 dengan IPK terendah 3,25 dan tertinggi 4.00 .

b. Variabel Self Directed Learning

Berdasarkan hasil data penelitian yang diperoleh maka dapat dideskripsikan masing-masing variabel penelitian. Deskripsi variabel dalam penelitian ini dideskripsikan berdasar perbandingan mean hipotetik dan 
mean empirik, serta deskripsi berdasar model distribusi normal.

Deskripsi berdasarkan perbandingan mean hipotetik dan mean empirik dapat ditunjukkan dengan melihat data penelitian. Menurut Azwar (1999) harga mean hipotetik dapat dianggap sebagai mean populasi yang diartikan sebagai kategori sedang atau menengah dalam kelompok subjek pada variabel yang diteliti. Setiap skor mean empirik yang lebih tinggi dari mean hipotetik secara signifikan dapat dianggap sebagai indikator tingginya keadaan kelompok subjek pada variabel yang diteliti. Sebaliknya, setiap skor mean empirik yang lebih rendah dari skor mean hipotetik secara signifikan maka dapat dianggap sebagai indikator rendahnya keadaan kelompok subjek pada variabel yang diteliti.

Deskripsi perbandingan mean empirik dan mean hipotetik dari data penelitian yang diperoleh dan dapat dilihat pada tabel berikut ini:

Tabel 2. Kategorisasi Skor Self Directed Learning

\begin{tabular}{|c|c|c|c|c|}
\hline Vrb1 & Skor & Jumlah & $\%$ & Kategori \\
\hline \multirow{4}{*}{ 官 } & $\mathrm{X} \leq 100$ & 0 & $0 \%$ & Sangat Rendah \\
\cline { 2 - 5 } & $100<\mathrm{X} \leq 133$ & 0 & $0 \%$ & Rendah \\
\cline { 2 - 5 } & $133<\mathrm{X} \leq 167$ & 14 & $28 \%$ & Sedang \\
\cline { 2 - 5 } & $167<\mathrm{X} \leq 200$ & 35 & $70 \%$ & Tinggi \\
\cline { 2 - 5 } & $200<\mathrm{X}$ & 1 & $2 \%$ & Sangat Tinggi \\
\cline { 2 - 5 } & Total & 50 & $100 \%$ & \\
\hline
\end{tabular}

Tabel 2. di atas menunjukkan bahwa self directed learning yang dimiliki subjek penelitian, 2 orang $(2 \%)$ memiliki self directed learning yang sangat tinggi, 35 orang $(70 \%)$ memiliki self directed learning yang tinggi, 14 orang $(28 \%)$ berada pada kategori sedang, tidak ada yang 
Sutipyo Ru'iya : Urgensi Self Directed Learning Mahasiswa Aktivis Di Era Revolusi Industri 4.0

memiliki self directed learning rendah apalagi sangat rendah. Kondisi ini menunjukkan bahwa sebagian besar subjek penelitian ini mempunyai self directed learning sangat yang tinggi.

c. Uji Korelasi Self Directed Learning dengan Prestasi

Akademik

Hasil uji normalitas data variabel self directed learning dengan prestasi akademik mahasiswa aktivis Program Studi Pendidikan Agama Islam adalah ternyata tidak normal. Sementara itu, normalitas data merupakan syarat uji statistik parametrik. Oleh karena data tidak memenuhi syarat, maka uji statistik dilanjutkan dengan uji statistik nonparametrik dengan menggunakan uji Spearmans"s dengan hasil pada tabel berikut:

Tabel IV.13. Tabel korelasi SDL dengan Prestasi Akademik Correlations

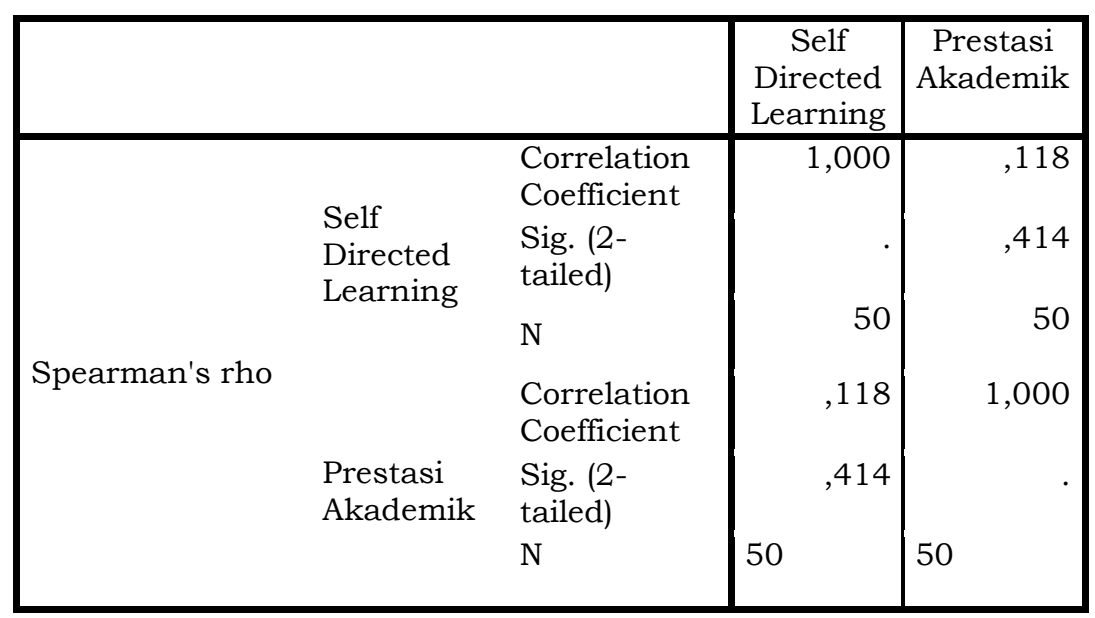

Dari tabel di atas diketahui bahwa nilai korelasi antara self directed learning dengan prestasi akademik mahasiswa aktivis Program Studi Pendidikan Agama Islam adalah sebesar 0,118 dengan makna hubungan yang 
Sutipyo Ru'iya : Urgensi Self Directed Learning Mahasiswa Aktivis Di Era Revolusi Industri 4.0

sangat rendah. Pengambilan keputusan bahwa hubungan antara gaya belajar dengan prestasi belajar dan self directed learning dan prestasi belajar mahasiswa aktivis di Program Studi Pendidikan Agama Islam Universitas Ahmad Dahlan sangat rendah berdasarkan kaidah yang disebutkan oleh Sugiyono (2007).

\section{KESIMPULAN}

Apabila dilihat dari kategori self directed learningnya, baik mahasiswa aktivis di Program Studi Pendidikan agama Islam, yang mempunyai IPK tiga peringkat tertinggi maupun yang mahasiswa yang mempunyai IPK tiga peringkat terendah adalah mahasiswa yang tergolong pada tingkat SDL tinggi. Sementara itu jika diperhatikan tabel 2. Kategorisasi Skor Self Directed Learning sangat jelas bahwa mahasiswa aktivis di Program Studi Pendidkan agama Islam mempunyai SDL yang baik, mereka mempunyai SDL yang sangat tinggi, tinggi, dan sedang. Dari data ini dapat diambil pelajaran bahwa Self Directed Learning mempunyai peranan yang sangat penting dalam peroleh prastasi akademik seorang mahasiswa.

Seperti yang banyak dilihat orang jika mahasiswa aktivis mempunyai banyak kegiatan maka mereka harus dapat membagi waktu yang baik, serta mempunyai kestabilan motivasi dalam belajar. Menurut Knowles (dalam, Tennant, 2006), dengan selfdirected learning maka akan timbul sebuah inisiatif yang diambil seorang individu, dengan atau tanpa bantuan orang lain, setelah dindividu tersebut mendiagnosa dan merumuskan tujuan belajarnya, mengidentifikasi sumber dan materi belajarnya, memilih dan menerapkan strategi belajar yang tepat dan mengevaluasi hasil belajarnya. 
Sutipyo Ru'iya : Urgensi Self Directed Learning Mahasiswa Aktivis Di Era Revolusi Industri 4.0

Begitu pula menurut Merriam \& Caffarella (dalam Gibbons, 2002) juga mengatakan bahwa orang yang sibuk namun dapat mengatur proses di mana seseorang mengambil inisiatif untuk merencanakan, melaksanakan, dan mengevaluasi cara belajarnya yang telah dan akan mereka lakukan sendiri, maka akan mencapai hasil yang maksimal. Demikian pula menurut Gibbons (2002) bahwa orang yang mempunyai SDL bagus akan dapat mpeningkatkan pengetahuan, keahlian, prestasi, dan mengembangkan diri yang dilakukan oleh seorang individu dengan cara banyak metode dalam berbagai macam situasi dan dalam waktu yang berbeda-beda pula. 
Sutipyo Ru'iya : Urgensi Self Directed Learning Mahasiswa Aktivis Di Era Revolusi

Industri 4.0

\section{DAFTAR PUSTAKA}

Ambedkar, V. 2012. Acievement Motivation and Achievement in English of Higher Secondary Students, Golden Research Thought, Vol 2 (6), hal 1-5.

Basr, A.S.H. 2012. Prestasi Akademik Mahasiswa Ditinjau Dari Kemampuan Literasi Media, Jurnal Dakwah, Vol. XIII, No. 1 Tahun 2012, hal. 15-38.

Baumgartner. (2003). Self-directed learning: A goal, process, and personal attribute. Columbus, $\mathrm{OH}$ : Center on Education and Traning for Employment.

Bire, A.L.; Geradus, U.; dan Josua Bire, J. 2014. Pengaruh Gaya Belajar Visual, Auditorial, Dan Kinestetik Terhadap Prestasi Belajar Siswa, Jurnal Kependidikan, Volume 44, Nomor 2, November 2014, hal. 168-174.

Caesari, Y.K.; Listiara, A.; dan Ariati, J. 2013. "Kuliah Versus Organisasi" Studi Kasus Mengenai Strategi Belajar Pada Mahasiswa Yang Aktif Dalam Organisasi Mahasiswa Pecinta Alam Universitas Diponegoro, Jurnal Psikologi Undip Vol.12 No.2 Oktober 2013, hal 164-175.

Chaplin, J.P. 2011. Kamus Lengkap Psikologi, Jakarta: PT. Raja Grafindo Persada.

Cox, T.D. 2013. Learning Styles and Admission Criteria as Predictors of Akademic Performance of Collage Frashmen. Institute for Learning Styles Journal. I, hal 1-10.

Gibbons, Maurice. (2002). The Self-Directed Learning Handbook: Challenging Adolescent Student to Excel. San Francisco: John Wiley \& Sons, Inc.

Manggala, I.K.A.; Suarni, N.K; dan Suarjana, I.M. 2013. Pengaruh Model Pembelajaran Self-Directed Learning Terhadap Hasil Belajar Matematika Siswa Kelas IV SD Lab Undiksha Singaraja Tahun Pelajaran 2012/2013, Jurnal Universitas Pendidikan Ganesha Singaraja. 1-10. 
Sutipyo Ru'iya : Urgensi Self Directed Learning Mahasiswa Aktivis Di Era Revolusi

Industri 4.0

Latipah, E. 2010. Self Regulated Learning dan Prestasi Belajar: Kajian Meta Analisis. Jurnal Psikologi. Vol. 37 (1), hal. 110129.

Papilaya, J.O. dan Huliselan, N. 2016. Identifikasi Gaya Belajar Mahasiswa, Jurnal Psikologi Undip Vol.15 No.1 April 2016, hal. 56-63.

Rachmawati, D.O. 2010. Penerapan Model Self-Directed Learning Untuk Meningkatkan Hasil Belajar Dan Kemandirian Belajar Mahasiswa, Jurnal Pendidikan dan Pengajaran, Jilid 43, Nomor 3, Oktober 2010, hlm.177-184.

Slameto. 2013. Faktor-Faktor yang Mempengaruhi Belajar. Jakarta: Bumi Aksara.

Sukmono, N.D. 2015. Metode Pembelajaran Self Directed Learning Berbasis ICT Dengan Pemanfaatan Game Android Berkarakter Untuk Pembelajaran Bahasa Indonesia, Prosiding Seminar Nasional Pendidikan Bahasa Indonesia 2015, hal. 247-254.

Tarmidi; Rambe, A.R.R. 2010. Korelasi Antara Dukungan Sosial Orang Tua dan Self-Directed Learning pada Siswa SMA, Jurnal Psikologi Volume 37, No. 2, Desember 2010, hal 216 223.

Tennant, M. 2006. Psuchology and Adulth Learning. New York: The Cromwell Press.

Uno, H.B. 2008. Proses Pembelajaran. Jakarta: Bumi Aksara.

Unzuntiryaki, E. 2007. Learning Style and High School Students Chemistry Achievement. Science Education International, 18 (1), hal. 25-37.

Winkel, W.S. 1996. Psikologi Pengajaran. Jakarta: Grasindo. 